\section{THE PATHOGENESIS OF CORONARY OCCLUSION}

By A. D. Morgan, M.A., M.D. Pp. 171, with 179 illustrations. Oxford: Blackwell Scientific Publications. 1956. $42 \mathrm{~s}$.

The author states in his preface that this book is based on material used for an M.D. thesis submitted to the University of Aberdeen in 1955, the main burden of which was to offer corroborative evidence for Professor Duguid's thrombogenic theory of coronary occlusion. After reading this preface one expected that the book would be a biased account of the pathogenesis of coronary occlusion and, whilst there is bias, it is not unduly prominent and the author has succeeded in presenting a sound review of the literature relevant to the morbid anatomy of this disease and of his own work on this subject.

His approach has been that of a morbid anatomist, and it is with this line of approach which he is mainly concerned, the equally promising biochemical approach to the pathogenesis of this disease being accorded only the barest outline. This book is recommended with the reservation that the title should have been the Morbid Anatomy of Coronary Occlusion. The word Pathogenesis has too wide a significance for its inclusion in the title of this sound, interesting and well-written monograph.

\section{LYMPHATICS, LYMPH AND LYMPHOID TISSUE}

By J. M. YofFeY, D.Sc., M.D., F.R.C.S., and F. C. Courtice, M.D., D.Phil., D.Sc. Pp. vii +5 I0, with 99 figures. London: Edward Arnold Ltd. 1956. 6os.

This is the second edition of a book which first appeared in 1940 under the authorship of J. M. Yoffey and C. K. Drinker, and which had already established itself as a standard work on the lymphatic system. In the present edition, owing to his untimely death, the place of Dr. Drinker has been taken by Dr. Courtice. The three authors who have been concerned with either the first or second edition, or both, have all made very substantial original contributions to our knowledge of this important system, a fact which in itself is a guarantee of the value of this comprehensive review of the whole field.

The general arrangement of the book has been altered very little but much of it has been re-written and much, chiefly descriptions of recent. work added. The approach is generally from the functional point of view as is natural in dealing with a system which gains much of its importance in relation to the maintenance of the fluid balance within the body. The accounts given of the composition and formation of extra-cellular body fluids, of the permeability of capillaries, and details concerning the flow and composition of lymph are excellent and are followed by an interesting summary of ideas concerning the biological significance of lymphatics and lymphoid tissue. The discussion of the lymphocyte itself brings together a very large amount of information, much of it unfortunately inconclusive, since the fundamental significance of this cell still appears to be obscure. There is a concluding chapter dealing with certain disorders of function involving the lymphatic system which have not been discussed elsewhere in the book.

The book may be very strongly recommended as a succinct account of the present position of knowledge of the lymphatic system, and should be of particular value to research workers in the clinical or pathological field. As in so many branches of science, the information it contains is scattered very widely in a large number of original papers, of which only those who have specialized in the subject can have detailed knowledge. Books such as this which collect information and make it easily accessible perform an essential function. For the general reader it would have been helpful if a little more had been done to provide critical summaries in some of the aspects of the subject dealt with, especially as so many are directly relevant to clinical and pathological problems of great importance. One realizes, however, that it is difficult to do this, and possibly premature, in a field where new knowledge is being added so rapidly and where the real significance of many observations is still obscure or controversial.

\section{ANTIBIOTIC MONOGRAPHS- 6 \\ Terramycin (Oxytetracycline)}

By Merle M. Musselman, M.D. Pp. 144. New York and London: Interscience Publishers Inc. 1956. \$4.00.

This forms one of a series of monographs edited by Henry Welch, Ph.D., and Felix Marti-Ibanez, M.D., dealing with specific aspects of the Antibiotics and their administration. Terramycin, with the other tetracyclines deserve special attention since they rank high in the series for general usefulness. Indeed, for their lack of toxicity and wide spectrum many people would place them next to Penicillin. Anyone wishing to find out the present position of these drugs cannot do better than refer to this book.

The author has dealt competently and lucidly with his subject, collecting together almost everything that could reasonably be needed in coming to conclusions on the usefulness of the agent. Twentysix pages of references are given at the end but, as is usual in this type of review, the sources are uneven and include both serious and extensive investigations and casual administration to small groups of patients with varying and unrelated clinical conditions.

The chapter on 'Combined Adrenocorticoid and Oxytetracycline 'Therapy' may well prove the most interesting to the clinical worker. The book confirms the impression that this drug is useful and remarkably free from serious side effects and reactions other than those due to the sterilization of mucous membranes and similar surfaces.

W.H.H. 